\title{
Fifty years of a public cassava breeding program: evolution of breeding objectives, methods, and decision-making processes
}

\author{
Hernán Ceballos ${ }^{1,2}\left[\right.$ Clair Hershey $^{3} \cdot$ Carlos Iglesias $^{4} \cdot$ Xiaofei Zhang $^{1,2} \oplus$
}

Received: 19 February 2021 / Accepted: 3 May 2021 / Published online: 4 June 2021

(c) The Author(s) 2021

\begin{abstract}
This paper reviews and analyzes key features from cassava breeding at the International Center for Tropical Agriculture (CIAT) over 50 years and draws lessons for public breeding efforts broadly. The breeding team, jointly with national program partners and the private processing sector, defined breeding objectives and guiding business plans. These have evolved through the decades and currently focus on four global product profiles. The recurrent selection method also evolved and included innovations such as estimation of phenotypic breeding values, increasing the number of locations in the first stage of agronomic evaluations, gradual reduction of the duration of breeding cycles (including rapid cycling for high-heritability traits), the development of protocols for the induction of flowering, and the introduction of genome-wide predictions. The impact of cassava breeding depends significantly on the type of target markets. When roots are used for large processing facilities for starch, animal feeding or ethanol production (such as in SE Asia), the adoption of improved varieties is nearly universal and productivity at the regional scale increases significantly. When markets and relevant infrastructure are weak or considerable proportion of the production goes for local artisanal processing and on-farm consumption, the impact has been lower. The potential of novel breeding tools needs to be properly assessed for the most effective allocation of resources. Finally, a brief summary of challenges and opportunities for the future of cassava breeding is presented. The paper describes multiple ways that public and private sector breeding programs can learn from each other to optimize success.
\end{abstract}

\section{Introduction}

This paper reviews and analyzes key features and results from cassava breeding at the International Center for Tropical Agriculture (CIAT) over 50 years and draws lessons for public breeding efforts broadly (Byerlee and Lynam 2020). The review discusses the evolution of objectives, strategies, methodologies, progress and outcomes; lessons learned; and perspectives on how to adapt and build for the future. It provides insights into the relevance of organizational structure

Communicated by Rajeev K. Varshney.

Hernán Ceballos

HernanCeballosL54@gmail.com

1 International Center for Tropical Agriculture (CIAT), Cali, USA

2 Alliance of Bioversity International and the International Center for Tropical Agriculture (CIAT), Alliance, Rome, Italy

3 Private consultant, Flinton, PA, USA

4 North Carolina State University, Raleigh, USA and decision-making processes, financial procurement and resource allocation, and value chains targeted.

The authors are former and current cassava breeders at CIAT, and span 40 of the center's 50 years of history. The CIAT story is only one part of complex and interdependent global efforts committed to improving livelihoods through better cassava varieties. Partnerships are at the core of the cassava breeding program modus operandi, as in the CGIAR centers in general. One of the most significant changes over the past 50 years has been the extraordinary growth in institutions (and private companies to a lesser extent) working on cassava and providing direct or indirect support to cassava breeding. We refer specifically to only a few of them, but acknowledge that any mention of CIAT learning and achievements is the result of many collaborating people and institutions, particularly with IITA (International Institute of Tropical Agriculture, Nigeria).

Systematic cassava breeding began with the creation of CIAT and IITA along with national programs (such as those in India, Thailand and Brazil) by 1970 . National programs in Africa and other Asian countries were created a few 
years later. The first varieties resulting from international programs began to emerge after 1985 .

\section{Institutional context}

\section{Origins}

In 2017, CIAT celebrated its 50th anniversary. Cassava research has been a core part of the center's portfolio since just a few years after its founding. Development of new varieties and training have been central activities, in support of national agricultural research systems (NARS). Germplasm was used directly as varieties for grower and end-user benefits, or as parents in NARS breeding efforts. There are several overviews of CIAT history, most notably Lynam and Byerlee (2017). Hershey (1994) provided an overall Cassava Program history during its first 25 years and Kawano (2003) described key results of breeding over 30 years. Malik et al. (2020) summarized the results of 50 years of cassava breeding and agronomy focused on SE Asia. The most granular treatment can be found in CIAT Annual Reports and numerous conference proceedings which detail breeding strategy, activities and results (see search options in https://cgspace.cgiar.org). Many dozens of peer-reviewed articles are published from results of CIAT's breeding research.

\section{Evolution of structure, funding and decision-making}

Table 1 places CIAT cassava breeding in four broadly defined eras and describes key characteristics of eachwith reference to structure, funding, objectives, and technological advances. We refer to elements of Table 1 throughout the paper, especially to place specific topics in the broader institutional context.

Cassava breeding efforts at CIAT were initially integrated within a broadly multidisciplinary research team, a model that inspired replication in many national research programs. This model allowed for an optimized allocation of resources based on a productive interaction among supporting areas of research. There was a common goal and each discipline contributed to it. The breeders drew on research and advice from entomologists, phytopathologists, agronomists, physiologists, economists and others to define strategy, breeding objectives and methods.

To promote and strengthen interactions within each discipline across different crops, CIAT changed its structure from programs to projects by the mid-1990s. In practice, however, what had been an integrated and coordinated effort toward common goals turned into an atomized, uncoordinated and often competing set of activities. This change took place as financial resources to the CGIAR were increasingly allocated to support restricted objectives, often fitting narrow priorities of donor institutions. The ultimate effect of these changes was a negative impact on the efficacy of cassava breeding. For example, whereas initially entomology research within the Cassava Program contributed to breeding efforts, in later years the entomology project competed for resources (to some extent) with cassava breeding. The administrative divisions that the project structure created were a burden that the program structure did not have. In spite of these silos, collaboration between different projects was still possible, albeit more difficult.

Simultaneously with the shift to a project structure, donors drove cassava research to become more focused on tools, i.e., developing cutting-edge technologies, rather than an outcome-driven agenda where the most appropriate methods and tools are selected to solve priority problems. Marker-assisted selection (MAS), for example, should not be an end in itself, but a tool to make cassava breeding toward specific goals more efficient.

In 2010, as the culmination of a reform and reorganization of the CGIAR system, root, tuber and banana crops (RTBs) were combined into a coordinated, integrated system-wide program in order to take advantage of the synergies among these vegetatively propagated starchy crops. This has had major impact on cassava breeding, allowing greater access to human resources and technologies applied across crops and across research centers. The benefits have been especially notable in upstream technologies, where costsharing and efficiencies of scale are critical, and in the social sciences input. The CGIAR system is currently implementing a "reformulation of its partnerships, knowledge, assets, and global presence, aiming for greater integration and impact in the face of the interdependent challenges facing today's world' (https://www.cgiar.org/food-security-impact/ one-cgiar/).

Cassava breeding has been almost exclusively carried out in the public sector, but at the same time has learned and benefitted from private sector experience, expertise and resources. Major distinctions between private and public breeding programs are: the way financial resources are procured; the decision-making processes on resource allocation; and, more importantly, that non-profitable markets are often targeted by public programs. Public research institutions are more likely to have organizational structures that are not as flexible and amenable to foster synergies as compared to the private sector. Pingali and Kelley pointed out in 2007 an important trend within the CGIAR system: the relatively rapid rise of restricted funding. In the early years, most contributions were unrestricted, but by 1990 this figure had fallen to $74 \%$ and by 2006 to $36 \%$. The trend has continued further and threatens the integrity of the system's research 


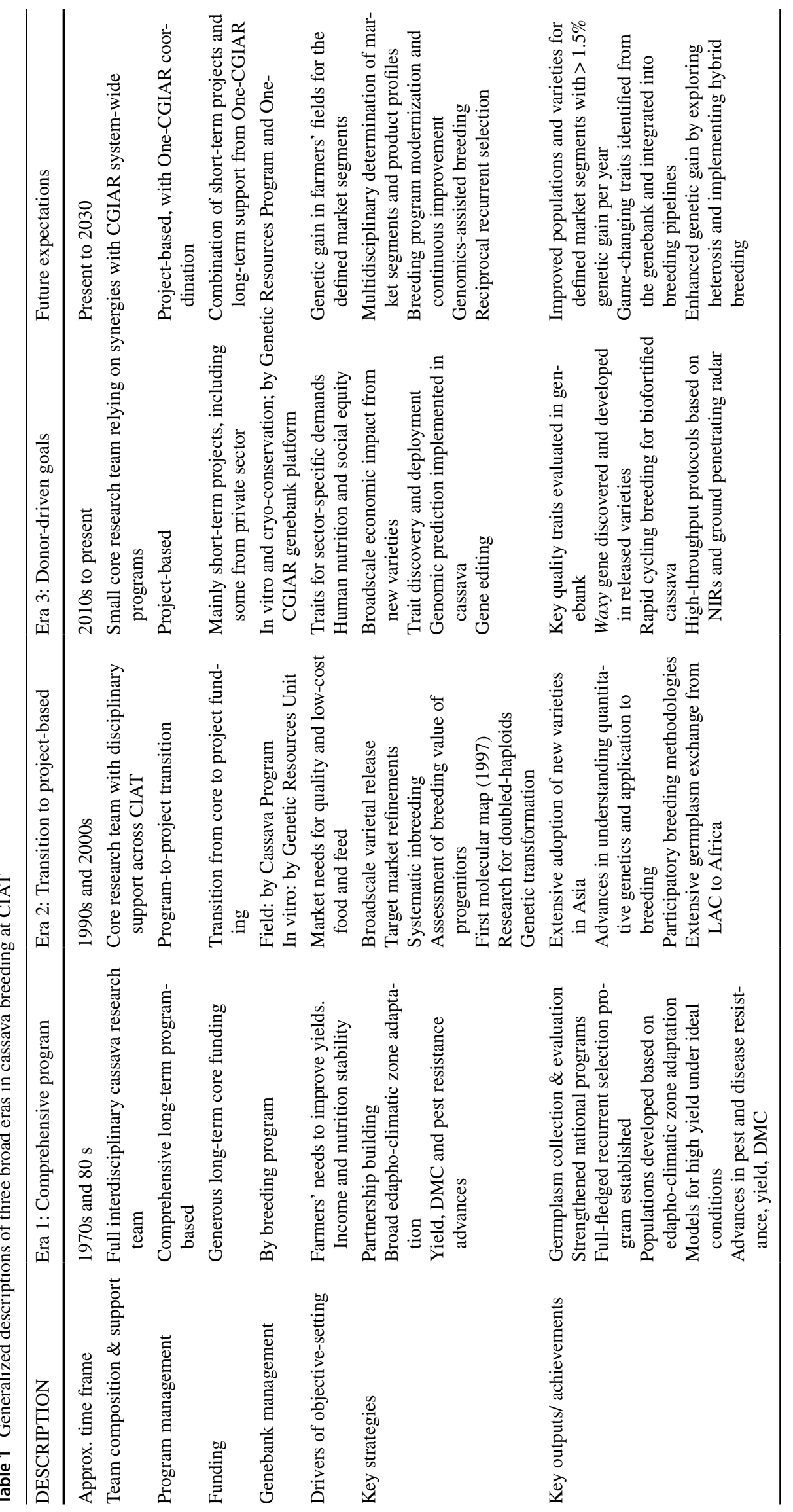


agenda. Stable and predictable funding is especially crucial for long-term research like plant breeding. As stated by these authors, "Disproportionate levels of restricted funding could move the CGIAR emphasis away from the generation of international public goods toward the adaptive and development end of the research spectrum. Piecemeal project funding could over emphasize short term outputs at the cost of reduced Center emphasis on long term strategic research. There is an overwhelming consensus now that the growing share of restricted funding is distorting research priorities, increasing transaction costs, and reducing the efficient use of resources."

Critical integration and programmatic planning, which contributed to the excellent progress achieved, were unfortunately lost. It is increasingly difficult to obtain resources to support the whole breeding structure, with a major shift toward short-term investment in novel technologies. Cassava breeding clearly benefits by having the flexibility and the resources to invest in high risk/high potential technologies; however, innovation should not be an end in itself. For sustained progress, there needs to be a practical balance between innovation and actual impact, as the best way to define the areas that benefit from financial support.

\section{Establishment and management of the germplasm collection}

Successful breeding relies fundamentally on suitable genetic diversity. CIAT initiated a series of germplasm collection expeditions as its first activity in the new cassava improvement efforts. By 1970, a large international collection from the center of origin of the crop, and from diverse ecosystems, had been established. In the five decades since then, CIAT has approximately doubled the number of landrace varieties with small collections and continuing introductions from partners. Today, 6155 accessions from 28 countries, several hundred elite breeding lines, and about 30 wild species of Manihot are conserved in the collection, using in vitro techniques. The collection has been widely used around the world. About 6500 shipments of accessions from the collection had been sent to 84 countries by the year 2019 (https:// ciat.cgiar.org/what-we-do/crop-conservation-and-use/cassa va-diversity/). Hershey (2010) reviewed cassava germplasm management on a global basis.

Understanding existing diversity in the germplasm collection received high priority throughout the history of the cassava breeding program. The CIAT Genetic Resources Program maintains a database including passport data, characterization and some agronomic data (CIAT cassava genebank database). All genebank evaluations (along with CIAT and IITA breeding program results, and more) are publicly available on the Cassavabase database managed by the Boyce Thompson Institute (https://btiscience.org/ourresearch/enabling-technologies/cassavabase-project/).

Initial priority (Kawano 2003) was given to evaluating the collection for harvest index, fresh root yield (FRY), and root dry matter content (DMC). This was followed by evaluation for pest and disease resistance and adaptation to multiple abiotic stresses. Although a wide range of useful variability has been identified in the collection (e.g., resistance to cassava green mites, whiteflies, bacterial blight, immunity to cassava brown streak virus (CBSD), waxy starch, etc.) there is still a need for a thorough screening to uncover additional value-added traits.

\section{Breeding objectives}

\section{Drivers and rationale for objective-setting}

CIAT has evolved through several overlapping phases of defining the drivers of objective-setting for cassava breeding, each building on new knowledge and a changing client landscape (Table 1). We broadly describe these drivers in terms of: farmers' needs for high productivity varieties; production system adaptation, sustainability, eco-efficiency and adaptation to climate change; meeting market needs for quality and sector-specific traits; and human health and social equity concerns. Globally, there are four clearly defined cassava product profiles: (i) biofortified cassava with high pro-vitamin A for nutrition enhancement; (ii) good cooking quality cassava (fresh or processed) for human consumption; (iii) high dry matter yield cassava for industrial use and animal feed; and (iv) special cassava with low amylose for food industry (Ceballos et al. 2007; 2011; 2013; Tran et al. 2021). Most cassava varieties released around the world would fit one (or two) of these product profiles. This section describes the dynamic approach assumed by CIAT in the definition of breeding objectives through time.

Cobb and co-workers correctly highlighted in 2019 the importance of properly defining breeding objectives. They also concluded that, because of the lack of business development units or marketing departments, "public-sector breeding typically takes at best an academic approach or at worst a speculative approach to determining trait targets and breeding strategies." This section provides evidence that CIAT and partner breeding programs, especially in SE Asia, have had unquestionable impact and have been successful by any measurable approach because of a sensible definition of the breeding objectives. CIAT's experience suggests that the success of a cassava breeding program does not depend on the presence or absence of business development units as part of the program itself (as suggested by Cobb et al. 2019), 
but rather on intimate knowledge of their target value chains and their operational efficiency, and the nature of these value chains.

\section{Improved farmer income and food security}

The CGIAR breeding programs were initially broadly driven by a need to curb food shortages and raise farmer incomes in regions of Asia, Africa and Latin America. This placed yield potential front and center as a breeding objective, and cassava was no different. Physiologists defined an ideotype for high yield, highlighting leaf area index as a critical determinant of yield potential under ideal conditions (Cock et al. 1979). Based on experiences from other crops, and with early experimental evidence in cassava, breeders focused strongly on harvest index as a selection criterion in the first years of breeding (Kawano 2003).

\section{Adaptation, stability and sustainability in diverse production systems}

As evaluation of germplasm expanded to different environments in the mid- to late 1970s, the CIAT program gained extensive new insights from soil science, entomology, pathology, physiology and agronomy. This new information allowed better understanding of the real-world conditions that farmers were facing, or were likely to face in the future, with the adoption of improved production practices and expansion into new production areas. With this growing knowledge base about the multiple biotic and abiotic factors impacting cassava growth and development, the cassava team took a closer look at best ways to stratify breeding objectives and develop populations for optimum genetic gain.

Our strategy aimed at varieties that responded well to low or moderate inputs (as opposed to adaptation in very low fertility or poorly managed conditions). More recently, climate change has increasingly influenced breeding objectives. Jarvis et al. (2012) suggested that changes in pest and pathogen populations would drive breeding objectives in cassava more than the direct effects of higher temperatures or drought.

\section{Targeted value chains and markets}

CIAT recognized early on the relevance that different value chains have in defining breeding objectives. Cassava farmers in SE Asia sell their harvests for the industrial production of starch, dried root chips for animal feeding and, more recently, ethanol. In these circumstances, defining a cassava ideotype is relatively simple: erect plant architecture, quick and uniform sprouting after planting, adequate harvest index, and maximized dry root yield (DRY) (Kawano and
Cock 2005). Root quality traits such as cyanogenic potential are largely irrelevant for these markets.

Boiled cassava and different ethnic food products such as gari, fufu and batons require specific root quality traits (e.g., low cyanogenic potential, mealiness, poundability and/or swelling power). The artisanal processing setups at the farm or village level (common for ethnic products) offer a sharp contrast with the large facilities for industrial products (Johnson et al. 2003; Scott 2021). The drivers and the establishment of breeding objectives for varieties for human consumption are generally more complex than those for industrial uses for several reasons: consumer preferences can be quite specific and vary significantly even within a given region (and sometimes between men and women); the scarcity of high-throughput phenotyping tools for preference-related attributes; little understanding of their biochemical and genetic basis (except for cyanogenic potential); trait preferences as expressed by farmers and consumers are complex and cannot easily be converted into quantifiable indicators for breeding objectives (Valle 2021) and strong GxE interactions. More importantly, onfarm consumption and local traditional markets tend to be resistant to change.

In the case of Latin America and the Caribbean (LAC), farmers would often sell the roots to the fresh market when the price was favorable, or otherwise, to processing facilities (which generally pay less compared to the fresh market, but can absorb much larger volumes). At the inception of the Cassava Program, most of the varieties grown by farmers in Colombia could be called dual-purpose. Accordingly, the breeding program initially attempted developing varieties that could serve two vastly different markets. During the 1980s, however, it became evident that the dual-purpose breeding objective was not feasible: genotypes with outstanding dry root yield (ideal for the industry) would be rejected, for example, because of high cyanogenic potential. As a result, two distinctive product profiles were defined: direct human consumption and industrial cassava.

A case study for Asia illustrates the impact of markets on success in breeding. Table 2 distinguishes Asian countries where cassava is mostly processed into starch, ethanol or dried chips from those where cassava is often consumed directly or processed into ethnic products. More than $95 \%$ of cassava grown in the first group involved improved varieties. On the other hand, adoption of improved varieties where cassava is consumed directly is around 55\%. Table 2 illustrates the way markets drive cassava breeders' objectives and influence adoption of improved varieties. When most of the roots are sold for processing at large facilities connected to international markets, the ideotype is simple and clearly attained (Gracen et al. 2018; Kawano 2003; Kittipadakul et al. 2017); adoption and replacement of improved varieties 
Table 2 Adoption of improved cassava varieties in different Asian countries (extracted from Labarta et al. 2017) and production parameters from years 2014-2018 (FAOSTAT 2020)

\begin{tabular}{llll}
\hline Country & $\begin{array}{l}\text { Adoption of improved varieties } \\
(\% \text { of total area planted) }\end{array}$ & $\begin{array}{l}\text { Area planted to cas- } \\
\text { sava (000 ha) }\end{array}$ & Average yield (t/ha) \\
\hline Countries where cassava is not commonly used for direct consumption & 287 & 26.9 \\
Cambodia & 100 & 547 & 19.0 \\
Vietnam & 95 & 1377 & 22.7 \\
Thailand & 99 & 2210 (total) & 22.9 (average) \\
Across 3 countries & 98.5 (average) & 214 & \\
Countries where cassava is mainly consumed and/or processed directly by farmers & \\
India & 69 & 849 & 23.9 \\
Indonesia & 47 & 226 & 12.0 \\
Philippines & 45 & 1289 (total) & 19.9 (average) \\
Across 3 countries & 54.5 (average) &
\end{tabular}

are remarkably high and dynamic; and markets provide effective feedback to breeders if the targets are not set properly (or if there are arising new constraints or opportunities (as illustrated later on the subsection on novel starches).

\section{Public health and social equity}

One of the central goals increasingly adopted across the CGIAR system is that breeders should address public health and social equity in developing product profiles. This can be immensely complex and difficult and is currently a matter of intensive research, including for cassava, and especially for gender issues (Mateo and Ortiz 2013; Forsythe et al. 2021). These concerns (not considered in Cobb et al. 2019) create an important distinction between the main driver of profit of private sector, and the wider scope of public breeding programs (https://www.corteva.com/who-we-are/outlook/ securing-food-through-sorghum.html).

\section{Examples of meeting needs through specific objectives and breeding solutions}

By following the collaborative CGIAR-NARS model, the CIAT Cassava Program has successfully defined and adjusted its breeding objectives through time. Successes and failures contributed along the way, as often occurs in any scientific endeavor. This section describes the way breeding objectives were initially defined, their evolution and perspectives for the future.

\section{Adaptation and performance in the face of biotic and abiotic constraints}

One of the first tasks of the breeder is often to assure that a population or a candidate variety is adapted in its target environment. In order to achieve a rational first-level stratification of breeding objectives, CIAT defined seven edapho-climatic zones (ECZs) (Hershey 1994). Each ECZ is characterized by a set of soil and climate characteristics, along with common pests and diseases, and provides the foundation for determining the target mega-environments of cassava production. Colombia has the good fortune to have a very diverse geography and climate, along with a wide range of the pests and diseases affecting cassava. This allowed CIAT to define testing sites for all the ECZs within Colombia (except the subtropics) and to identify homologs globally (Hyman 2020).

\section{Improved nutritional quality}

The innovative approach to improve nutritional quality in different crops (biofortification) arose entirely within public breeding programs (Bouis and Saltzman 2017) and included cassava since its inception (Bouis et al. 2017). These efforts were duly acknowledged by awarding the 2016 World Food Prize in recognition of the work developing orange-fleshed sweet potato. By the late 1990s, initial screening was conducted to assess variation in nutritional quality within the cassava germplasm collection (Iglesias et al. 1997). The program eventually focused just on pro-vitamin A carotenoids (Chávez et al. 2005). Significant progress was achieved after ten years of breeding (Ceballos et al. 2013), based initially on a rapid-cycling approach specifically designed to take advantage of the high-heritability of carotenoids content in cassava (Fig. 1). To achieve and sustain genetic progress, the program developed appropriate sampling strategies (Ortiz et al. 2011) and created an efficient high-throughput phenotyping approach based on near-infrared spectroscopy (Belalcazar et al. 2016; Sánchez et al. 2014). Public breeding programs are in a unique position to set visionary breeding objectives that are beneficial to society, even though these benefits are not initially evident to consumers. Biofortification is now a widespread breeding objective worldwide, including within the private sector. 


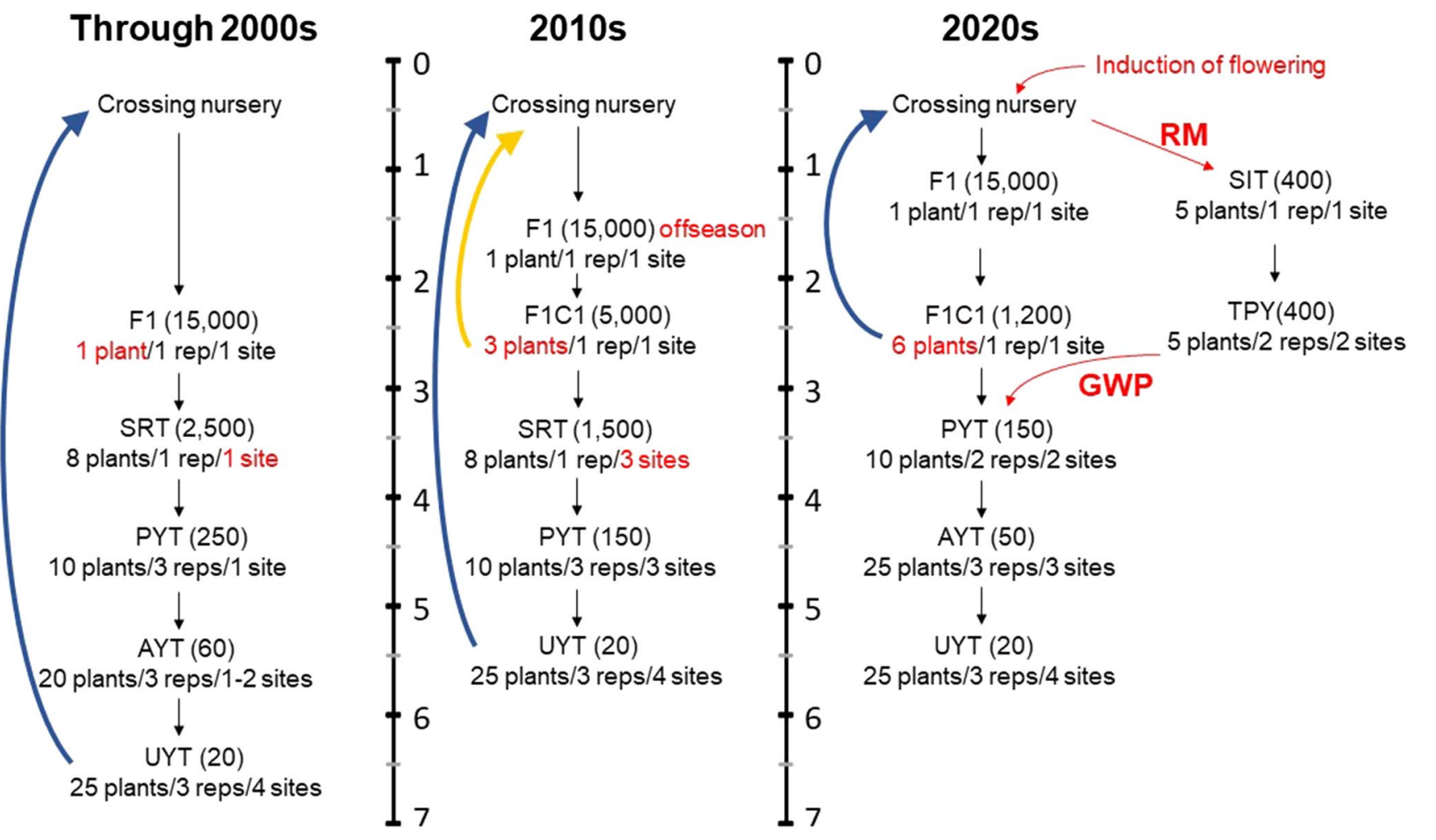

Fig. 1 The evolution of breeding schemes at CIAT. F1: seedling nursery; F1C1: cloned seedling nursery; SRT: single row trial; PYT, AYT and UYT: preliminary, advanced and uniform yield trials, respectively; GWP: genome-wide prediction; SIT: seed increase trial; TPY:

\section{Discovery and exploitation of novel starch quality traits}

Cassava is the second most important source of starch worldwide, after maize. The starch sector requested in 2000 a waxy starch (amylose-free) cassava variety and provided financial support to screen the germplasm collection in search of the trait. Eventually, a waxy starch mutation was identified in 2006 (Ceballos et al. 2007). A second mutation (small-granule starch) was discovered around the same time, but in a population resulting from gamma-ray mutagenesis of true seeds (Ceballos et al. 2008).

In the years following the discovery of these mutations, intensive work was conducted to assess their functional properties (Rolland-Sabaté et al. 2012; 2013; Sánchez et al. 2010), which expanded the markets for cassava-based products. More importantly, research agreements were signed to develop waxy commercial varieties for SE Asia and South America with close involvement and the financial support of starch companies. The first generation waxy-starch cassava varieties were released in Thailand in 2013 (Rojanaridpiched et al. 2020; Thai Tapioca Development Institute, 2017), and the first commercial processing of waxy cassava starch in Colombia took place in 2019. Starch quality research has training population yield trials; RM: rapid multiplication. Upward arrows indicate the duration of each breeding cycle (the orange arrow is for the rapid-cycling for high-carotenoids breeding)

reflected the dynamism behind defining product profiles in close interaction with relevant market players.

\section{High and stable dry matter content (DMC)}

High and stable DMC is a trait highly appreciated by farmers and processors alike. The quality of cassava roots (and their selling price) fluctuates with the age of the plant and the environmental conditions prior to harvest. Farmers typically harvest cassava near the end of the dry season because DMC normally reaches a maximum and the duration of the storage period of stems for next season's planting is shorter. Erratic rainfall is one of the most common consequences of climate change and has been observed in the sub-humid environment of Colombia.

Cassava germplasm with high DMC has already been developed and deployed. It is desirable, however, to add the requirement that these high DMC levels are relatively stable (Ceballos et al. 2011). However, screening for stable DMC is not a trivial endeavor and is highly affected by GxE interactions (Sagrilo et al. 2008). Management complicates matters further (GxExM). Trials were grown for up to 18 months, disrupting the normal operations and creating logistic challenges. For several years, CIAT selected genotypes with 
high DMC at normal harvesting age (10-12 MAP) and combined with capacity to maintain acceptable levels after the arrival of the rains (15-18 MAP). Extended harvest (e.g., at $18 \mathrm{MAP}$ ) is a common practice in subtropical regions of South America, particularly in Southern Brazil (Sagrilo et al. 2008). A set of eight experimental clones selected for high and stable DMC is currently under evaluation for their release as commercial varieties in Colombia (Lenis et al. 2018). Ideal genotypes are those with a competitive performance (in terms of FRY and DMC) in normal harvests and show a minimum reduction in DMC in extended harvests, after the arrival of the rains. In the latter case, unstable dry matter is mainly determined by the mobilization of starch from the roots at or after stressful conditions.

\section{Understanding and dissecting quality traits for human consumption}

The adoption of improved cassava varieties for boiling and ethnic uses is limited. Several factors contribute to this situation, including the fact that released varieties often fail to meet the required quality traits (Eriksson et al. 2018). One major bottleneck to breeding is the limited information regarding the genetic and biochemical basis determining root quality traits for different end uses, and suitable high-throughput phenotyping protocols. In contrast, potato breeders have made significant advances in understanding tuber quality traits and developing phenotyping tools that facilitate selection (Dufour et al. 2021; Morris and Taylor 2019; Sharma et al. 2020). The project RTBfoods: Breeding Roots, Tubers and Banana products for end-user preferences (https://rtbfoods.cirad.fr) is an ambitious initiative to elucidate basic information regarding root quality traits. Several research articles regarding root quality traits and post-harvest processing have recently been published (Alamu et al. 2021; Bechoff et al. 2018; Dufour et al. 2021; Escobar et al. 2021; Goddard et al. 2015; Iragaba et al. 2021; Luna et al. 2021; Ndjouenkeu et al. 2021; Teeken et al. 2018, 2021; Thiele et al. 2021; Tran et al. 2021). The availability of this critical knowledge and reliable high-throughput phenotyping protocols will improve the efficiency of breeding for root quality traits.

\section{Preparing cassava for the $\mathrm{CO}_{2}$ levels of $\mathbf{2 0 5 0}$}

Cassava is photosynthetically highly efficient among $\mathrm{C}_{3}$ species (El-Sharkawy et al. 1992; El-Sharkawy 2014; 2016). The crop competes with maize in the starch, animal feed and ethanol value chains. Increased concentration of atmospheric $\mathrm{CO}_{2}$ is one of the causes of global warming and it is expected to continue rising through the year 2050. This rise has beneficial effect on photosynthetic efficiency and productivity in cassava (Rosenthal et al. 2012; Ruiz-Vera et al.
2020), and may reduce the physiological advantage of C4 crops, such as maize, over cassava. Breeders should exploit the opportunity to select and breed for positive responses to rising $\mathrm{CO}_{2}$ levels and minimize detrimental effects (if any). Crops can be grown in the field under set $\mathrm{CO}_{2}$ levels using free-air concentration enhancement (FACE) rings. So far, however, these trials have only been conducted in temperate regions of North America and would benefit from replication in the tropics where cassava is grown.

\section{Optimizing breeding strategies, methods and tools}

\section{Filling gaps for basic information}

Public sector breeding often covers crops that offer lower opportunities for profit by breeding enterprises. The absence of commercial opportunities is closely linked with a lower level of investments for research. In the case of cassava, there was a remarkable lack of basic information at the time CIAT and IITA were created. In spite of huge advances, there remains a significant knowledge gap relative to other major crops. As one important example, critical information regarding the flowering biology of cassava (receptivity of stigmas, pollen tube growth, embryo development) has only been addressed in the past three years (Lentini et al. 2020a; 2020b; 2020c; Pineda et al. 2020a; 2020b; Ramos-Abril et al., 2019). Unfortunately, this lack of relevant basic information resulted in a serious bottleneck for the development of new technologies such as protocols for the production of doubled-haploids. Likewise, limited information about the genetic and biochemical determination of root quality traits has had detrimental effect on the development of varieties targeting human consumption of cassava.

\section{Optimizing phenotypic recurrent selection}

Many breeding programs have used the same basic conventional cassava breeding method for decades, with variations introduced as new information became available (Ceballos et al. 2012, 2017; Gonçalves Fukuda et al. 2002; Jennings and Iglesias 2002; Kawano and Cock 2005; Hershey 2020a, b). The first step involves the production of full- or halfsib seed in crossing nurseries. A major challenge of seed production in cassava is the association between quantity of seed produced and plant growth habit. Early, frequent and abundant flowering is closely associated with a highly branched plant architecture, which is undesirable (Ceballos et al. 2015). Farmers prefer an erect architecture, which results from late (or absent) flowering. Producing seeds from progenitors with erect plant architecture is, therefore, 
a challenging task. Only recently, progress to accelerate the production of botanical seed has been achieved through different strategies (Hyde et al. 2019; Pineda et al. 2020a; 2020b; Silva Souza et al. 2018). Cassava progenitors are heterozygous and even full-sib families are genetically very diverse. Each $F_{1}$ seedling is genetically distinct and several years are required to produce enough stem cuttings for multilocation testing (the multiplication rate in cassava can vary widely, but is about 1:10 on average).

Figure 1 depicts the evolution of breeding schemes. Starting in the 2010s, the seedling nursery (F1) was planted in the off season and grown for only six months. The F1C1 stage with three plants per genotype was added as the source of planting materials for the following single row trial (SRT), which could then be planted in three locations (red text). The following stages are the preliminary (PYT), advanced (AYT) and uniform (UYT) yield trials with increasing number of plants per plot, but AYT was no longer grown in the 2010s. Selected genotypes were incorporated to the crossing nurseries (blue upward arrows). Rapid-cycling (Ceballos et al. 2013) was implemented for high-heritability traits such as carotenoids content (orange upward arrows).

The development and implementation of the flowerinducing technology shortened the duration of crossing nurseries in the 2020s (Fig. 1). The F1 is grown for seven months, which allows F1C1s to have six plants per genotype and then PYT to grow in two locations. Selections for PYT will be made based on the total genetic value predicted using genome-wide prediction (GWP). The F1C1 clones with the best predicted breeding value will be cycled back to crossing nurseries as progenitors for the next cycle of improvement (black upward arrows). The GWP training population is selected from the breeding population based on the pedigree. Rapid multiplication (RM) is performed in green house to obtain five plantlets from each seedling. The plantlets are transplanted into the seed increase trial (SIT). The following growing cycle, the training population yield trials (TPY) are established at two locations for phenotyping. The SIT and $\mathrm{F} 1 \mathrm{C} 1$ clones are genotyped for genome-wide prediction.

The traditional evaluation process has been extensively described (Jennings and Iglesias 2002; Ceballos et al. 2012; Hershey 2020a, b). Selection in the seedling nurseries (F1), which at CIAT involves $\approx 15$ thousand genotypes per product profile, is only for general vigor and high-heritability traits such as resistance to specific pests and diseases and occasionally for carotenoids content or starch quality traits. In Africa, drastic selection takes place to eliminate genotypes susceptible to CMD. Selected seedling plants are cloned and single row trials (SRT), preliminary (PYT), advanced (AYT) and uniform (UYT) yield trials follow with a gradual reduction of genotypes evaluated while plot size, number of replications and locations involved increase.
Starting in the 2010s (Fig. 1), a modification of the breeding scheme was implemented to overcome logistical problems in breeding for high-carotenoids (Belalcazar et al. 2016), but the new experimental design was quickly implemented for every product profile, to improve accuracy and reliability. The F1 is germinated in August each year (six months earlier than in the traditional system). Seedlings are grown in the field for only six months. At this age, selection for key traits (vigor, plant architecture, roots with yellow parenchyma or waxy starch, reaction to thrips) can be made but only three stem cuttings can be taken. Each selected genotype is thus cloned and planted in a new stage (F1C1) at the normal planting time and grown for a year. This approach allows growing identical SRTs in three locations, overcoming a major weakness of the original system (Fig. 1). Genotype-by-environment (GxE) interactions limit the reliability of SRTs (Adjebeng-Danquah et al. 2017; Akinwale et al. 2011; Chipeta et al. 2017; Mtunguja et al. 2016; Peprah et al. 2016; Ssemakula, and Dixon 2007). Preliminary results of this innovation indicate that only $25-35 \%$ of clones are simultaneously selected in two of the three locations, highlighting the effect of $\mathrm{GxE}$ in these non-replicated trials. Changes implemented in the 2020s are described later.

\section{Exploiting phenotypic breeding value}

Based on breeding theory, CIAT investigated the possibility to exploit breeding values for more effective progenitor selection. Single row trials (SRT) include several full- and half-sib families, each one represented by varying numbers of genotypes. It was common that a given progenitor was used as a parent in more than one family. Data were taken from both selected and rejected genotypes in the SRT, allowing for an approximation of the general combining ability (GCA) of each progenitor (Ceballos et al. 2004). A large data set involving more than 30,000 plots through 14 years of evaluation in the sub-humid environment tracked the performance of thousands of genotypes evaluated from SRT through uniform yield trials (UYT), and was later published (Ceballos et al. 2016a, b). In spite of promising early results, selecting progenitors based on GCA proved inefficient. Large within-family genetic variation relative to differences in breeding values (Ceballos et al. 2016a) and the relevance of non-additive genetic effects (Ceballos et al. 2015, 2017; Wolfe et al. 2016) are partially responsible for the limited impact that selecting for GCA had.

Another important factor is phenotypic instability. The phenotype of a given genotype in the SRT may not be the same four years later at the UYT (Joaqui et al. 2016). Breeding clonally propagated crops requires consideration of the impact of the overall quality of the planting material. Epigenetic factors, nutritional and physiological status, pathogens 
and beneficial endophytes (Bräutigam et al. 2013; Jansky and Spooner 2018) may affect the general performance of the same genotype through the sequential stages of evaluation depicted in Fig. 1. These factors may partially explain the poor correlations observed in the phenotypic evaluation of the same genotypes through these different stages of selection (Joaqui et al. 2016) and, to some extent, justify a lengthy evaluation process. Phenotypic instability complicates considerably the breeders' equation described in Cobb et al. 2019.

\section{Genotyping and genomic prediction to accelerate genetic gain}

The rapid improvement of DNA sequencing technologies has driven down the cost to less than one penny per megabase of DNA sequence in 2020 (www.genome.gov/). Sequencing-based marker technologies, in turn, are dramatically reducing the cost of genome-wide marker discovery. High density genome-wide markers, combined with statistical tools, have the potential to enhance conventional plant breeding, not only in identifying and validating trait markers for MAS and implementing genome prediction (Rabbi et al. 2020; Wolfe et al. 2017), but also in characterizing and managing genetic variance and performing optimum contribution selection when making crosses (Hallander and Waldmann 2009; Wang et al. 2016a, b). Collaborating with Beijing Genomics Institute, CIAT is using whole genome sequencing to discover genome-wide markers from cassava breeding populations. The high-density markers are used in association mapping and linkage mapping to identify major QTLs in breeding populations, and provide detailed information about the haplotypic diversity, to design diagnostic markers for MAS. Moreover, with the genotypic data, we are able to calculate the genomic best linear unbiased prediction (GBLUP) of breeding materials, and make more accurate selection in variety development than pedigree BLUP or replication mean.

The genotyped breeding populations also serve as the training populations for genomic prediction. Considering the determinant of genetic relationship on the prediction accuracy, we use a small subset of the breeding population, selected based on the pedigree, as the training population. The clones in the training population and the breeding population are siblings, which leads to high prediction accuracy. On the other hand, rather than genotyping the entire breeding population $(\sim 10,000$ seedlings per product profile), we rely on the cheap seedling nursery to get rid of more than $80 \%$ clones of the breeding population, and only genotype the selected clones for genomic prediction. Moreover, the training population starts from seeds and we are able to share the seeds with collaborators, with a simple quarantine inspection process. The training population is evaluated in the collaborator's environment, and the collaborator-specific genomic prediction models will be developed for progenitor selection from the breeding population at CIAT. We will use the progenitors to produce seeds as improved populations and share them with collaborators for variety development.

Genomic predictions, therefore, will facilitate the germplasm sharing and enhance CIAT's capacity of improving populations for NARS. Now we are implementing this genomic prediction strategy with the breeding programs in Southeast Asia to develop cassava varieties with high and stable dry matter yield and CMD resistance. Compared with the current conventional breeding scheme, a genomic prediction-based breeding scheme will reduce duration of the selection cycle by at least two years (Fig. 1). The genomic prediction strategy is also implemented in the breeding pipelines for the introgression of CMD and CBSD resistance into the high pro-vitamin A pipeline and good cooking quality pipeline for Africa. To bring all breeding data together to inform breeding decisions, we fully use CassavaBase to manage phenotypic data, genotypic data and pedigree data (Fernandez-Pozo et al. 2015).

\section{Development and application of high-throughput phenotyping tools}

CIAT and partners have contributed proactively to developing reliable and affordable phenotyping protocols to overcome bottlenecks in the breeding process. The use of nearinfrared spectroscopy (NIRs) on fresh root samples greatly facilitated quantification of carotenoids contents (Sánchez et al. 2014; Belalcazar et al. 2016; Alamu et al. 2021). It is now widely used in different biofortification projects. The use of ground penetrating radar for the non-destructive assessment of root growth through time is another ambitious innovation in which CIAT actively participated (Delgado et al. 2017). This technology would be relevant for assessing early bulking, an elusive trait often demanded by farmers. Important progress for facilitated measurements of cooking time has recently been published (Tran et al. 2021), which will facilitate breeding for varieties consumed directly after boiling the roots. Aeroponics techniques are now refined and should be an option for rapid screening of early rooting characteristics (Selvaraj et al. 2019). Remote sensing via drones to analyze growth patterns is under development (Selvaraj et al. 2020). Combined with data from underground root development, this can provide valuable tools to integrate real-time whole-plant development with yield potential, and ultimately result in high-throughput phenotyping tools. 


\section{Participatory approaches in priority setting and evaluation strategies}

In response to the limited adoption of varieties for direct consumption in resource-limited farming conditions, the cassava breeding program, along with the socio-economics unit at CIAT, pioneered the development and application of farmer participatory approaches. Beginning in 1986, CIAT and Colombia's National Research Program worked collaboratively to develop, refine and apply a methodology for utilizing farmers' expertise and knowledge about their variety needs (Hernandez 1993; Hershey 2020c). Participatory approaches are likely to facilitate development of varieties that out-perform those developed through conventional methods when they are applied in low-yield cropping systems and in specific locations.

Participatory breeding has evolved over time. Mother-baby trials (Atlin et al. 2001; 2002; Ramisch 2012; Snapp 2002) combine larger trials done on-station or onfarm (mother trials), with smaller on-farm, farmer-managed trials of 1-3 technologies (baby trials). More recently, the TRICOT design (triadic comparisons of technology options) has been suggested and tested (Steinke et al. 2017; van Etten et al. 2019a; b; 2020), including in the NextGen cassava project (https://www.nextgencassava.org).

\section{Outputs and impact of cassava breeding}

Crop genetic improvement has historically been the bread and butter of the CGIAR. Improved germplasm for use by national programs, either for direct release or as parent material, is a classic international public good with demonstrated large spillovers across regions and countries (Maredia and Byerlee 2000). There are several ways in which results from cassava breeding can be measured, ranging from the biological outputs (genetic gains), to adoption by farmers (economic impact). The training and education of future plant breeders are another important contribution and a primary role of the public plant breeder (Fowler 2005), although it is difficult to assign a quantitative value to this contribution. Equally difficult to quantify is the overall impact that cassava research at CIAT has had in consolidating the cassava breeding system, which includes NARS.

\section{Genetic gains}

Estimations of the impact from breeding at the CGIAR centers, from the time of their creation, on the productivity of many crops have been published (Alston et al., 2020; Evenson and Gollin 2007; Pingali 2012; Pingali and Kelley 2007; Renkow and Byerlee 2010). For cassava, gains are very diverse across African countries, but there are several studies demonstrating significant increases in productivity and sizable returns on investment (Eriksson et al. 2018). The genetic gain per year in Africa has been estimated at 1.3\% for FRY and 1.2\% for dry root yield (Okechukwu and Dixon 2008). Similarly, genetic gains in Thailand were estimated to be 2.50 and $1.06 \%$ and per year for FRY and DMC, respectively (Kawano 2003). During the 1975-2015 period, annual estimated gains were $0.23 \mathrm{t} / \mathrm{ha}$ for FRY, $0.13 \%$ for starch content and $0.12 \mathrm{t} / \mathrm{ha}$ for root dry yield (Ceballos et al. 2020; Kittipadakul et al. 2017). Rapid-cycling for enhanced carotenoids content resulted in consistent annual increases of 2.06 $\mathrm{ug} / \mathrm{g}$ for total carotenoids content (fresh weight basis) over an eight years period (12\% per year gains). These remarkable gains could be achieved because of the high heritability for this trait (Ceballos et al. 2013).

\section{Economic impact}

Johnson and co-workers in 2003 estimated economic benefits from the use of improved cassava varieties in 1998 alone at (million US\$) 12.9 for LAC ( 7 countries), 335.7 for Africa (20 countries) and 99.5 for SE Asia (5 countries). When total investments in cassava breeding at CIAT are considered, the internal rate of return was $22 \%$. The impact of breeding within the CGIAR has been achieved in spite of a sharp decline in share of its core funding (funding with considerable flexibility for internal institutional management) over time, falling from 25 to $16 \%$ between 1992 and 2005 (Pingali and Kelley 2007). Investments in cassava breeding at CIAT fell by 30\% from 1990 to 1997 (Johnson et al. 2003).

In addition to this reduction in the overall investment in crop breeding, a considerable proportion of the investment was diverted to new emerging technologies (namely genetic transformation and molecular markers research). However, to date, there is no commercially grown genetically modified cassava. Twenty-five years after the publication of the first molecular map of cassava, there is no cost/benefit report of MAS. Outputs from conventional cassava breeding risk a slowdown as a result of competing investments in novel technologies that have not yet had any measurable impact in productivity. As stated by Cobb et al., (2019), breeding teams need to evaluate carefully the impact of any new technology and such evaluation is long overdue. Contrary to suggestions in the literature, there is no evidence that the rates of return to research within the CGIAR had declined over time (Pingali 2012).

\section{Sustainability and yield stability}

Yield stability is important especially for poor farmers whose food security and livelihoods are vulnerable to chronic or fluctuating biotic and abiotic stresses. Recent evidence suggests that later generations of improved crop 
varieties have stabilized yields in comparison with those they replaced (Renkow and Byerlee 2010). In the case of cassava, resistance or tolerance to prevalent abiotic or biotic stresses is among the most relevant traits considered by the breeders. For example, in the late 1980s and early 1990s, a new strain of CMD (UgV/EACMV-Ug) emerged in East Africa. Losses to cassava production have been estimated at 140,000 tons annually, which is equivalent to USD 14 million (Legg and Thresh 2000). However, no major CMD epiphytotic has been reported in the last 30 years in Africa after the identification and deployment of new sources of resistance (Eriksson et al. 2018).

Public breeding programs in East Africa have now released varieties tolerant/resistant to CBSD, another threat to cassava production in Africa (Kawuki et al. 2016). Several accessions from CIAT's germplasm collection were found to be immune to CBSD at the greenhouse level and are now undergoing field trials (Sheat et al. 2019). This is the first time such a strong type of resistance has been reported for CBSD. Incorporation of genes for resistance to CMD and CBSD into elite varieties of cassava in SE Asia and Africa will be the most effective method to limit damage from the viruses (pre-emptively for CBSD in W Africa and SE Asia). However, the lack of homozygous progenitors makes the simple introgression through back-crossing impossible (discussed further below).

Developing varieties tolerant to abiotic stresses (particularly drought) is another output from cassava breeding programs, particularly for sub-humid and semi-arid environments (Burns et al. 2010; Okogbenin et al. 2014). However, cassava as a species is quite drought tolerant, and the impact on yield stability of varieties selected specifically for additional tolerance has not been reported so far.

\section{Public health and social equity}

Breeding programs generally aim to improve the income of users of new varieties, but also may impact their nutrition and health status through biofortification (Bouis et al. 2017). This is an area of impact not considered by Cobb and co-workers (2019). CGIAR breeding programs (including those for cassava at CIAT and IITA) made significant efforts to improve the nutritional quality of different crops. These efforts did not translate in yield gains, but they certainly resulted in the delivery of valuable public goods. Their impact, however, will only be measurable in vulnerable populations, several years after biofortified varieties have been released. Meenakshi and co-workers demonstrated in 2007 that biofortification can have a significant impact on the burden of micronutrient deficiencies in a large number of countries in Africa, Asia and Latin America. More importantly, it can do so in a highly cost-effective manner.

\section{Challenges and new opportunities}

We conclude the overview of cassava breeding by suggesting some priorities for the future based on current or arising challenges, and the tools, technologies and institutional innovations that can contribute to optimized breeding.

\section{Understanding and expanding the germplasm base}

Hershey (2010) described the future needs for new initiatives to expand and ensure optimized use of the germplasm base available to cassava breeders. While there is ample evidence that breeding has not generally been constrained by lack of diversity, for a very wide array of target traits, there remain regions of likely new and high diversity that have not been adequately collected. Many of the wild Manihot species are at risk of extinction because of land clearing for agriculture and are vulnerable to climate change. New germplasm collection is currently not on the radar for major donors, and a case needs to be made that will change this.

CIAT is currently in the process of genotyping its cassava collections using DarTseq (to be completed in 2021). This will be the first full, high-resolution genotyping of a complete genebank of a major crop, and will be an invaluable resource for understanding the crop's evolution, defining gene pools, gene discovery and more. Attention should be paid to managing genotypic data and phenotypic data linked with the test environment information and making the data publicly available and easily accessible. The genotypic data and phenotypic data are linked with the plots and the metainformation of yield trials. The features in CassavaBase provide the reference for developing a database to manage genebank information.

\section{Promising arising tools and technologies}

The identification of useful traits in CIAT's germplasm collection (for example waxy starch and resistance to CBSD) illustrate the potential of trait discovery for the future of the crop. It is reasonable to assume that new traits could be discovered within the wealth of genetic diversity encompassed by the global germplasm collection. The huge progress in understanding the Arabidopsis genome and the comparison with the sequenced $M$. esculenta genome could yield valuable information about gene functions in cassava. An array of useful traits ranging from herbicide tolerance, starch functional properties, haploid inducers, etc., could be identified using molecular sieving tools such as Eco-TILLING (Comai et al. 2004; Kumar et al. 2017). In spite of the early evidence demonstrating its feasibility (Duitama et al. 2017), there has been no further follow-up by the biotechnology community. 
Gene editing is a reality in many crops, including cassava (Gomez et al. 2019; Mehta et al. 2019). A key issue regarding this technology is the gene sequence to be targeted. The haploid inducer technology has been widely used in maize and other monocots (Kalinowska et al. 2019) and, through wide crosses, in potato (Rokka 2009). Orthologues of the genes responsible for inducing haploids in monocots have been recently identified in dicots (Zhong et al. 2020). There is ongoing research at CIAT targeting a sequence expected to induce haploids in cassava. This initiative illustrates what has been a productive collaboration between field breeding and biotechnology. The development of protocols for the induction of earlier flowering and seed production (Pineda et al. 2020a; 2020b) facilitates inbreeding through successive self-pollinations. However, the easiest and fastest way to produce inbred lines would be through the induction of haploidy through the haploid inducer technology or tissue culture approaches (Lentini et al. 2020a, 2020b; Perera et al. 2012).

\section{The challenges and opportunities of trait introgression}

Trait introgression is a key process in plant breeding and is likely to become even more prevalent in the age of gene discovery and editing. Back-crossing is a widely used and highly effective breeding method for trait introgression (Xu and Crouch 2008). However, it cannot be implemented in the classical manner in cassava, because of the lack of inbred progenitors. The cassava breeding project at CIAT introgressed the single recessive waxy gene to commercial varieties in SE Asia and South America. The introgression necessarily requires multiple generations of recombination to reduce the impact of the less desired alleles from the source parent of the waxy mutation(s). The first varieties to be released in Thailand, for example, had a starch productivity equivalent to that of Rayong 1 , a landrace variety formally released in 1975 (Ceballos et al. 2020): about 45 years of breeding progress were reversed by introgressing a single recessive trait. Excellence in cassava breeding urgently requires an efficient way to introgress useful traits into selected backgrounds.

The issue of trait introgression has long been considered by cassava breeders (Ceballos et al. 2015). The introgression of waxy starch targets a specific, high-value sector of the starch industry. More urgent and global is the need to introgress resistance to CMD in SE Asia after the recent introduction and rapid spread of the disease in that region (Wang et al. 2016a, b). Although the best source of resistance to the disease (CMD2) has been fully characterized and markers have been developed (Kuon et al. 2019; Wolfe et al. 2016), its introgression remains highly inefficient (Ceballos et al. 2020). Similarly, the introgression of CBSD resistance identified from South American landraces (Sheat et al. 2019) into African varieties would be unnecessarily cumbersome. The obvious response is that cassava breeding must shift toward the use of inbred progenitors, so that efficient backcross (and MAS) could be finally implemented. Excellence in cassava breeding relies on controlling the way alleles segregate, rather than just tracking them.

\section{Pre-breeding and population improvement as a precursor to hybrid development}

Recurrent selection is an efficient way to improve populations by gradually and consistently shifting allelic frequencies in the desired direction. By definition, recurrent selection operates on additive effects (e.g., GCA) or genomic estimated breeding value (GEBV) in phenotypic recurrent and genomic prediction, respectively. In contrast, when the final product is a hybrid rather than a population, a relevant part of the genetic variability defining the performance is non-additive.

Optimized cassava breeding requires efficient exploitation of non-additive genetic effects (Ceballos et al. 2015, 2016a, 2017). As stated by Bernardo (2020): "The genotypic value is that of the candidate itself, whereas the breeding value is reflected by the mean of the candidate's progeny when it is mated with random individuals." Therefore, in cassava and other vegetatively propagated crops, the prediction of total genetic value should be used for the advancement of clones toward later stages and potential commercial release. Advancing clones based on breeding values (additivity) could miss those combinations that have the added dominance and epistatic boost that would make them excel.

In the case of cassava, pre-breeding work through genomic predictions, complemented by standard phenotypic evaluation and selection protocols to identify outstanding hybrids has been proposed (de Oliveira et al. 2012; Wolfe et al. 2017). A key assumption is (as it was in the maize pipelines analyzed by Good in 1990), that successive cycles of population improvement would increase the probability of identifying superior hybrids. A process diagram of the breeding strategy should allow for transparency and accountability, and helps breeding management teams develop key performance indicators that assess the value of activities in delivering genetic gains (Cobb et al. 2019). The cost/benefit comparison of alternative cassava breeding approaches should be documented to support decision-making and research design.

\section{Exploiting heterosis and hybrid breeding}

Heterosis is a critical phenomenon not only for commercial hybrid and RTB crops (Batte et al. 2020; Gopal 2014; Gurmu et al. 2018; Mendoza and Haynes 1974; Musembi 
et al. 2015; Quero-García et al. 2009), including cassava (Ceballos et al. 2015), but also for self-pollinated ones (Lin et al. 2020). Additive genetic effects explain a large proportion of the variability for most traits, and most can be efficiently improved through modern genomic tools (de Oliveira et al. 2012; Okeke et al. 2017; Wolfe et al. 2016; 2017). Although non-additive effects account for a smaller proportion of the genetic variability, they are critical for the performance of outstanding hybrids (Melchinger et al. 2007).

Maize remains the reference crop regarding the exploitation of heterosis. Key elements for the success of maize breeding have been the identification of heterotic groups and the use of inbred progenitors (Mikel and Dudley 2006). However, the identification of heterotic patterns such as those found in temperate maize has so far proven to be difficult in cassava. Genetic distances, as in the case of many crops, are not a good predictor for specific combining ability in cassava (Ceballos et al. 2016b). There are ongoing efforts to identify heterotic patterns among IITA populations (Peter Kulakow, personal communication). Such research is critical for a systematic exploitation of heterosis through reciprocal recurrent selection schemes and/or development of fully or partially inbred lines.

Recent breakthrough developments in potato breeding imitate maize breeding (Hosaka and Sanetomo 2020; Jansky et al. 2014, 2016, 2018; Lindhout et al. 2011, 2017). The possibility of developing inbred progenitors has been fundamental for this quantum leap taken by private potato breeding companies. If public sector breeding programs are to take advantage of the lessons from the private sector (as suggested by Cobb et al. 2019), then future cassava breeding should explore options to shift to the use of fully or partially inbred lines. Partial progress in that direction has already been made, with promising results regarding flower induction (Pineda et al. 2020a, 2020b), important progress toward the development of a protocol for the production of doubled-haploids in cassava (Lentini et al. 2020a, 2020b, 2020c), and the ongoing efforts to edit the cassava genome for the expression of haploid induction.

\section{Reverse breeding and haplotype breeding value}

Successful hybrids are the combined result of positive general and specific combining ability effects. For example, KU50 is an outstanding cassava hybrid clone widely grown for decades in several Asian countries (Gracen et al. 2018). In a way, KU50 equals the memorable cross between Mo17 and B73 in maize. The heterotic pattern in this maize hybrid has been fundamental for the hybrid maize industry (Mikel and Dudley 2006; Stuber 1994). Over the years, different advanced lines were derived from the two original inbreds, gradually increasing the superiority of the resulting hybrids.
A key difference between the cassava (KU50) and maize (Mo17xB73) hybrids is that KU50 cannot be re-made because its progenitors (R1 and R90) are not inbred. There are ways, however, to approximately define the respective haplotypes from R1 and R90 that produced the KU50 hybrid. Since R1 and R90 are still available, it is theoretically feasible to use reverse genetic approaches (Dirks et al. 2009; Guan et al. 2015; Wijnker et al. 2012) to produce partially or fully inbred lines that closely resemble the targeted haplotypes that defined KU50. This is a complex proposal, but once these inbred lines have been derived, a KU50 version, combining resistance to CMD and CBSD, could be developed and deployed in Asia and Africa. Having access to the inbred components of a strong heterotic pattern could be the basis for powerful alternative breeding approaches.

\section{Improving seed systems}

A major challenge of cassava breeding programs compared with private seed businesses is that the former historically lack efficient systems to produce and distribute planting material of the new varieties. This delays the uptake and penetration of new varieties at the farm level, regardless of their genetic merit. While rapid propagation systems have been available, and continually refined for many years, practical, commercially viable systems have been nearly nonexistent. There are ongoing efforts, primarily supported by the Bill and Melinda Gates Foundation in West Africa, to develop rapid multiplication approaches to produce diseasefree planting materials. A goal of these systems is to make them sustainable as for-profit ventures.

\section{Breeding system decision-making and execution of research processes}

To maximize genetic gains and the economic impact of cassava breeding programs, decision-making should arise from a consensus among the different actors of the team and be driven by client interests. An interdisciplinary cassava research team is required to determine the market segments and product profiles and develop and implement the Stage\&Gate system. Cobb et al. (2019) present a perceived dichotomy between "the -omics and machine learning and artificial intelligence potential of transforming plant breeding programs toward a data-rich, evidence-based, and team-oriented process and away from the romantic tradition of an individual breeder as an artist." This dichotomy, however, is fallacious. Plant breeders, by default, use best evidence in their decision-making; they are comfortable handling large databases and they typically work in teams. As an example of a field breeder searching for evidence-based proof of the advantages of a breeding approach, a large database ( $>30,000$ plots) 
was used to assess the value of breeding value in cassava (Ceballos et al. 2016a). It is also an example of reversing an earlier decision based on the evidence obtained from available data (Ceballos et al. 2004). Applied breeders, by nature, take a long-term, integrated view of challenges and opportunities, and adopt best-bet methods and tools. They usually avoid technology-based biases, their ultimate objective being to maximize genetic gain, impact at field level, and incorporation of the tools and expertise of the molecular breeder or gene-editing specialists, without bias for or against any particular class of tools. There is a key principle that is widely accepted: without high-quality phenotypic data, molecular tools are not useful. Quality of phenotypic data does not only include proper field management, but also careful management of planting material and reliable tracking of samples and data.

Major challenges that public cassava breeding programs face, from our perspective, are given as follows:

- Donors increasingly define the research agenda (Pingali and Kelley 2007).

- Novel breeding tools have become an end by themselves and their actual impact on improving breeding efficiency has not been properly assessed.

- Breeders and research managers need to work more closely together in order to assure that assignment of resources is based on the full range of complex goals of a breeding program.

- Innovation cannot become an end by itself, where new technologies are seen as better than old ones, irrespective of their actual impact. In the case of cassava, biotechnological approaches have been slower to yield results and tangible impact than many proponents promised.

Finally, we want to highlight an example of efforts to reach an integration between different actors in a cassava breeding program: the NextGen Project, managed by Cornell University. Many different collaborators and areas of expertise have been integrated toward a common goal (Mbanjo et al. 2021). Upstream genomic approaches have been combined with conventional and participatory breeding approaches. End-user demands have been incorporated into the definition of breeding objectives. Finally, key biological bottlenecks such as those related to flowering biology have been addressed and successfully solved (Hyde et al. 2019; Pineda et al. 2020a, 2020b). These principles and approaches epitomize the future of successful cassava breeding.

Author contributions statement $\mathrm{HC}$ wrote the initial draft of the document and consolidated inputs by the other co-authors; $\mathrm{CH}$ and $\mathrm{CI}$ participated in defining the outline of the article and revising the different versions; $\mathrm{XZ}$ wrote the description of the new breeding scheme and revised the earlier version. All authors worked as cassava breeders at CIAT. XZ is the current breeder.

Funding The authors thank the UK's Foreign, Commonwealth \& Development Office (FCDO) and the Bill \& Melinda Gates Foundation (Grant INV-007637 http://www.gatesfoundation.org) for their financial support as well as the Roots, Tubers and Bananas Program of the CGIAR.

Availability of data and material This manuscript does not have additional associated data.

\section{Declarations}

Conflicts of interest The authors declare no conflict or competing interests.

Open Access This article is licensed under a Creative Commons Attribution 4.0 International License, which permits use, sharing, adaptation, distribution and reproduction in any medium or format, as long as you give appropriate credit to the original author(s) and the source, provide a link to the Creative Commons licence, and indicate if changes were made. The images or other third party material in this article are included in the article's Creative Commons licence, unless indicated otherwise in a credit line to the material. If material is not included in the article's Creative Commons licence and your intended use is not permitted by statutory regulation or exceeds the permitted use, you will need to obtain permission directly from the copyright holder. To view a copy of this licence, visit http://creativecommons.org/licenses/by/4.0/.

\section{References}

Adjebeng-Danquah J, Manu-Aduening J, Gracen VE, Asante IK, Offei S (2017) AMMI stability analysis and estimation of genetic parameters for growth and yield components in cassava in the forest and guinea savannah ecologies of Ghana. Inter $\mathrm{J}$ Agron. https://doi.org/10.1155/2017/8075846

Akinwale MG, Akinyele BO, Odiyi AC, Dixon AGO (2011) Genotype $\mathrm{x}$ environment interaction and yield performance of 43 improved cassava (Manihot esculenta Crantz) genotypes at three agro-climatic zones in Nigeria. Br Biotechnol J $1(3): 68-84$

Alamu EO, Nuwamanya E, Cornet D et al (2021) Near-infrared spectroscopy applications for high-throughput phenotyping for cassava and yam: a review. Int J Food Sci Technol 56:1491-1501. https://doi.org/10.1111/ijfs.14773

Atlin GN, Cooper M, Bjornstad A (2001) A comparison of formal and participatory breeding approaches using selection theory. Euphytica 122:463-475

Atlin GN, Paris T, Courtois B (2002) Sources of variation in participatory varietal selection trials with rainfed rice: implications for the design of mother-baby trial networks. In: Bellon MR, Reeves J (eds) Quantitative analysis of data from participatory methods in plant breeding, pp 36-43. CIMMYT, Mexico DF. https://repository.cimmyt.org/xmlui/handle/10883/909

Batte M, Nyine M, Uwimana B et al (2020) Significant progressive heterobeltiosis in banana crossbreeding. BMC Plant Biol 20:489. https://doi.org/10.1186/s12870-020-02667-y

Bechoff A, Tomlins K, Fliedel G et al (2018) Cassava traits and end-user preference: relating traits to consumer liking, sensory perception, and genetics. Crit Revs Food Sci 58(4):547-567 
Belalcazar J, Dufour D, Andersson MS et al (2016) High-throughput phenotyping and improvement in breeding cassava for increased carotenoids in the roots. Crop Sci 56:2916-2925

Bernardo R (2020) Reinventing quantitative genetics for plant breeding: something old, something new, something borrowed, something BLUE. Heredity 125:375-385

Bouis HE, Saltzman A (2017) Improving nutrition through biofortification: a review of evidence from HarvestPlus, 2003 through 2016. Glob Food Sec 12:49-58

Bouis HE, Saltzman A, Low J, Ball A, Covic N (2017) The way forward. Afr J Food Agric Nutr Dev 17(2):12130-12141. https:// doi.org/10.18697/ajfand.78.HarvestPlus17

Bräutigam K, Vining KJ, Lafon-Placette C et al (2013) Epigenetic regulation of adaptive responses of forest tree species to the environment. Ecol Evol 3:399-415

Burns A, Gleadow R, Cliff J, Zacarias A, Cavagnaro T (2010) Cassava: the drought, war and famine crop in a changing world. Sustainability 2:3572-3607

Byerlee D, Lynam JK (2020) The development of the international center model for agricultural research: A prehistory of the CGIAR. World Dev 135:105080

Ceballos H, Iglesias CA, Pérez JC, Dixon AGO (2004) Cassava breeding: opportunities and challenges. Plant Mol Biol 56:503-515

Ceballos H, Sánchez T, Morante N et al (2007) Discovery of an Amylose-free Starch mutant in cassava (Manihot esculenta Crantz). J Agric Food Chem 55:7469-7476

Ceballos H, Sánchez T, Denyer K et al (2008) Induction and identification of a small-granule, high-amylose mutant in cassava (Manihot esculenta Crantz). J Agric Food Chem 56:7215-7222

Ceballos H, Ramirez J, Bellotti AC, Jarvis A, Alvarez E (2011) Adaptation of cassava to Changing Climates. In: Hatfield JL, LotzeCampen H (eds) Yadav S Redden B. Crop Adaptation to Climate Change. Wiley-Blackwell, Hoboken, pp 411-425

Ceballos H, Kulakow P, Hershey C (2012) Cassava breeding: current status, bottlenecks and the potential of biotechnology tools. Trop Plant Biol 5:73-87

Ceballos H, Morante N, Sánchez T et al (2013) Rapid cycling recurrent selection for increased carotenoids content in cassava roots. Crop Sci 53:2342-2351

Ceballos H, Kawuki RS, Gracen VE, Yencho GC, Hershey CH (2015) Conventional breeding, marker assisted selection, genomic selection and inbreeding in clonally propagated crops: a case study for cassava. Theor Appl Genet 128:1647-1667

Ceballos H, Pérez JC, Orlando JB et al (2016a) Cassava breeding I: the value of breeding value. Front Plant Sci 7:1227. https://doi.org/ 10.3389/fpls.2016.01227

Ceballos H, Becerra LA, Calle F et al (2016b) Genetic distance and heterosis in cassava. Euphytica 210:79-92

Ceballos H, Morante N, Calle F, Lenis JI, Salazar S (2017) Cassava Breeding. In: Hershey, C (eds) Achieving sustainable cultivation of cassava Volume 2: Genetics, breeding, pests and diseases, Burleigh Dodds Science Publishing, Cambridge, UK (ISBN: 9781786760043. www.bdspublishing.com, pp 49-90

Ceballos H, Rojanaridpiched C, Phumichai C, Kittipadakul P, Iglesias C, Gracen VE (2020) Excellence in cassava breeding: perspectives for the future. Crop Breed Genet Genom. https://doi.org/ $10.20900 / \operatorname{cbgg} 20200008$

Chávez AL, Sánchez T, Jaramillo G et al (2005) Variation of quality traits in cassava roots evaluated in landraces and improved clones. Euphytica 143:125-133

Chipeta MM, Melis R, Shanahan P, Sibiya J, Benesi IRM (2017) Genotype $\mathrm{x}$ environment interaction and stability analysis of cassava genotypes at different harvest times. J Anim Plant Sci 27:901-919
Cobb JN, Juma RU, Biswas PS et al (2019) Enhancing the rate of genetic gain in public-sector plant breeding programs: lessons from the breeder's equation. Theor Appl Genet 132:627-645

Cock JH, Franklin D, Sandoval G, Juri P (1979) The ideal cassava plant for maximum yield. Crop Sci 19:271-279

Comai L, Young K, Till BJ et al (2004) Efficient discovery of DNA polymorphisms in natural populations by Ecotilling. Plant $\mathrm{J}$ 37(5):778-786

Delgado A, Hays DB, Bruton RK, Ceballos H, Novo A, Boi E, Selveraj MG (2017) Ground penetrating radar: a case study for estimating root bulking rate in cassava (Manihot esculenta Crantz). Plant Methods 13:65. https://doi.org/10.1186/s13007-017-0216-0

de Oliveira EJ, Vilela de Resende MD, da Silva Santos, et al (2012) Genome-wide selection in cassava. Euphytica 187:263-276

Dirks R, van Dun K, de Snoo CB et al (2009) Reverse breeding: a novel breeding approach based on engineered meiosis. Plant Biotechnol J 7:837-845

Dufour D, Hershey C, Hamaker BR, Lorenzen J (2021) Integrating end-user preferences into breeding programmes for roots, tubers and bananas. Int J Food Sci Technol 56:1071-1075. https://doi. org/10.1111/ijfs. 14911

Duitama J, Kafuri L, Tello D et al (2017) Deep assessment of genomic diversity in cassava for herbicide tolerance and starch biosynthesis. Comput Struct Biotechnol 15:185-194

El-Sharkawy MA (2014) Global warming: causes and impacts on agroecosystems productivity and food security with emphasis on cassava comparative advantage in the tropics/subtropics. Photosynthetica 52:161-178

El-Sharkawy MA (2016) Prospects of photosynthetic research for increasing agricultural productivity, with emphasis on the tropical C4 Amaranthus and the cassava C3-C4 crops. Photosynthetica. https://doi.org/10.1007/s11099-016-0204-Z

El-Sharkawy MA, Mejía de Tafur S, Cadavid LF (1992) Potential photosynthesis of cassava as affected by growth conditions. Crop Sci 32:1336-2134

Eriksson D, Akoroda M, Azmach G, Labuschagne M, Mahungus N, Ortiz R (2018) Measuring the impact of plant breeding on subSaharan African staple crops. Outlook Agr. https://doi.org/10. $1177 / 0030727018800723$

Escobar A, Rondet E, Dahdouh L et al (2021) Identification of critical versus robust processing unit operations determining the physical and biochemical properties of cassava-based semolina (gari). Int J Food Sci Technol 56:1311-1321. https://doi.org/10.1111/ ijfs. 14857

Evenson RE, Gollin D (2007) Contributions of national agriculture research systems to crop productivity. In: Evenson R, Pingali $\mathrm{P}$ (eds) Handbook of agricultural economics, vol 3. Elsevier, New York, pp 2419-2459

FAOSTAT (2020). Food and Agriculture Organization of the United Nations. Rome, Italy. http://faostat.fao.org

Fernandez-Pozo N, Menda N, Edwards JD et al (2015) The sol genomics network (SGN)-from genotype to phenotype to breeding. Nucleic Acids Res. https://doi.org/10.1093/nar/gku1195

Forsythe L, Tufan H, Bouniol A, Kleih U, Fliedel G (2021) An interdisciplinary and participatory methodology to improve user acceptability of root, tuber and banana varieties. Int J Food Sci Technol 56:1115-1123. https://doi.org/10.1111/ijfs. 14680

Fowler C (2005) Politics of plant breeding. Plant Breed Rev 25:21-55

Goddard J, Panhorst Harris K, Kelly A, Cullen A, Reynolds T, Anderson L (2015) Root, tuber, and banana textural traits: a review of the available food Science and consumer preferences literature. Evans School Policy Analysis and Research (EPAR), University of Washington, Brief No, p 295

Gomez MA, Lin ZD, Moll T et al (2019) Simultaneous CRISPR/Cas9mediated editing of cassava eIF4E isoforms nCBP-1 and nCBP-2 
reduces cassava brown streak disease symptom severity and incidence. Plant Biotechnol J 17:421-434

Gonçalves Fukuda WM, de Oliveira \& Silva S, Iglesias C, (2002) Cassava breeding. Crop Breed Appl Biotech 2:617-638

Good RL (1990) Experiences with recurrent selection in a commercial seed company. Proceedings for the forty-fifth annual corn $\&$ sorghum industry research conference. American Seed Trade Association, pp 81-92

Gopal J (2014) Heterosis breeding in potato. Agric Res 3(3):204-217

Gracen VE, Kogsil P, Napasintuwong O, Duangjit J, Phumichai C (2018) The story of Kasetsart 50. The most important cassava variety in the world. Kasetsart University, Bangkok

Guan YX, Wang BH, Feng Y, Li P (2015) Development and application of marker-assisted reverse breeding using hybrid maize germplasm. J Integr Agric 14:2538-2546

Gurmu F, Hussein S, Laing M (2018) Combining Ability, heterosis, and heritability of storage root dry matter, beta-carotene, and yield-related traits in sweetpotato. HortScience 53:167-175

Hallander J, Waldmann P (2009) Optimum contribution selection in large general tree breeding populations with an application to Scots pine. Theor Appl Genet. https://doi.org/10.1007/ s00122-009-0968-7

Hernández-R LA (1993) Evaluación de nuevas variedades de yuca con la participación de agricultores. Working document no.130, CIAT, Cali, Colombia

Hershey CH (1994) Research for development: The CIAT Cassava Program. Centro Internacional de Agricultura Tropical (CIAT), Cali, Colombia. https://hdl.handle.net/10568/78019

Hershey CH (2010) A global conservation strategy for cassava (Manihot esculenta) and wild Manihot species. https://www.croptrust. org/wp/wp-content/uploads/2014/12/cassava-strategy.pdf

Hershey CH (2020a) Cassava genetic improvement: theory and practice. Chapter 12. Seedling management and selection. p. 183202. International Center for Tropical Agriculture (CIAT). Cali, Colombia. https://cgspace.cgiar.org/handle/10568/110397

Hershey CH (2020b) Cassava genetic improvement: theory and practice. Chapter 13 . Managing preliminary through advanced trials. International Center for Tropical Agriculture (CIAT). Cali, Colombia. 443 p. https://cgspace.cgiar.org/handle/10568/110397 pp 203-228

Hershey CH (2020c) Cassava genetic improvement: theory and practice. Client participation in variety development. International Center for Tropical Agriculture (CIAT). Cali, Colombia. 443 p. https://cgspace.cgiar.org/handle/10568/110397 pp 331-350

Hosaka K, Sanetomo R (2020) Creation of a highly homozygous diploid potato using the $\mathrm{S}$ locus inhibitor (Sli) gene. Euphytica 216:169. https://doi.org/10.1007/s10681-020-02699-3

Hyde PT, Guan X, Abreu V, Setter TL (2019) The anti-ethylene growth regulator silver thiosulfate (STS) increases flower production and longevity in cassava (Manihot esculenta Crantz). Plant Growth Regul 90:441-453

Hyman GG (2020) Edapho-climatic-map-of-cassava-CIAT-2003. jpg, Global Climate Regions for Cassava, https://doi.org/10. 7910/DVN/WFAMUM/0OVLW9, Harvard Dataverse, V2

Iglesias C, Mayer J, Chavez L, Calle F (1997) Genetic potential and stability of carotene content in cassava roots. Euphytica 94:367-373

Thai Tapioca Development Institute - TTDI (2017). Wonders of Tapioca. TTDI, Bangkok, Thailand

Iragaba P, Hamba S, Nuwamanya E, Kanaabi M, Nanyonjo RA, Mpamire D, Muhumuza N, Khakasa E, Tufan HA, Kawuki RS (2021) Identification of cassava quality attributes preferred by Ugandan users along the food chain. Int J Food Sci Technol 56:1184-1192. https://doi.org/10.1111/ijfs. 14878

Jansky SH, Spooner DM (2018) The evolution of potato breeding. Plant Breed Rev 41:169-211
Jansky S, Chung Y, Kittipadukal P (2014) M6: A diploid potato inbred line for use in breeding and genetics research. J Plant Regist 8:195-199

Jansky SH, Charkowski AO, Douches DS et al (2016) Reinventing potato as a diploid inbred line-based crop. Crop Sci 11:1-11

Jarvis A, Ramirez-Villegas J, Campo BVH, Navarro-Racines C (2012) Is cassava the answer to African climate change adaptation? Trop Plant Biol 5:9-29

Jennings DL, Iglesias CA (2002) Breeding for crop improvement. In: Hillocks RJ, Thresh JM, Bellotti AC (eds) Cassava: biology, production and utilization. CABI, Wallingford, pp 149-166

Joaqui BO, Lenis JI, Calle F et al (2016) Cassava breeding II: phenotypic correlations through the different stages of selection. Front Plant Sci 7:1649. https://doi.org/10.3389/fpls.2016.01649

Johnson NL, Manyong VM, Dixon AGO, Pachico D (2003) The impact of IARC genetic improvement programmes on cassava. In: Evenson RE, Gollin D (eds) Crop variety improvement and its effect on productivity: the impact of International Agricultural Research. CABI, Wallingford, pp 337-355

Kalinowska K, Chamas S, Unkel K et al (2019) State-of-the-art and novel developments of in vivo haploid technologies. Teor Appl Genet 132:593-605

Kawano K (2003) Thirty years of cassava breeding for productivity biological and social factors for success. Crop Sci 43:1325-1335

Kawano K, Cock JH (2005) Breeding cassava for underprivileged: institutional, socio-economic and biological factors for success. J Crop Improv 14:197-219

Kawuki RS, Kaweesi T, Esuma W et al (2016) Eleven years of breeding efforts to combat cassava brown streak disease. Breed Sci. https:// doi.org/10.1270/jsbbs. 16005

Kittipadakul P, Kongsil P, Phumichai C (2017) Breeding cassava for higher yield. In: Hershey C (ed) Achieving sustainable cultivation of cassava, vol 2. Genetics, breeding, pests and diseases. Burleigh Dodds, Cambridge, pp 139-170

Koundinya AVV, Ajeesh BR, Hegde V, Sheela MN, Mohan C, Asha KI (2021) Genetic parameters, stability and selection of cassava genotypes between rainy and water stress conditions using AMMI, WAAS BLUP and MTSI. Sci Hort 281:109949

Kumar APK, McKeown PC, Boualem A et al (2017) TILLING by Sequencing (TbyS) for targeted genome mutagenesis in crops. Mol Breed. https://doi.org/10.1007/s11032-017-0620-1

Kuon JE, Qi W, Schläpfer P (2019) Haplotype-resolved genomes of geminivirus-resistant and geminivirus-susceptible African cassava cultivars. BMC Biol. https://doi.org/10.1186/ s12915-019-0697-6

Kvitschal MV, Soares Vidigal PS, Fo., Scapim CA, et al (2006) Evaluation of phenotypic stability of cassava clones by AMMI analysis in northwestern Parana state. Crop Breed App Biotech 6:236-241

Labarta R, Wossen T, Phuong Le D (2017) The adoption of improved cassava varieties in South and South East Asia. Proceedings of the $9^{\text {th }}$ ASAE International Conference: Transformation in agricultural and food economy in Asia. Bangkok, Thailand

Legg JP, Thresh JM (2000) Cassava mosaic virus disease in East Africa: a dynamic disease in a changing environment. Virus Res 71:135-149

Legg J, Somado EA, Barker I et al (2014) A global alliance declaring war on cassava viruses in Africa. Food Secur. https://doi.org/10. 1007/s12571-014-0340-x

Legg J, Lava Kumar P, Makeshkumar T et al (2015) Cassava virus diseases: biology, epidemiology, and management. Adv Virus Res 91:85-142

Lenis JI, Rosero EA, Morante N, Salazar S, Ceballos H (2018). Experiences in breeding for high and stable dry matter content in cassava roots. IVth GCP21 International Cassava Conference, Cotonou, Benin 
Lentini Z, González A, Tabares E, Buitrago ME, Wêdzony M (2020) Studies on gynogenesis induction in cassava (Manihot esculenta Crantz) unpollinated ovule culture. Front Plant Sci 11:365. https://doi.org/10.3389/fpls.2020.00365

Lentini Z, Tabares E, Buitrago ME (2020) Vibratome sectioning and clearing for easing studies of cassava embryo formation. Front Plant Sci. https://doi.org/10.3389/fpls.2020.01180

Lentini Z, Restrepo G, Buitrago ME, Tabares E (2020) Protocol for rescuing young cassava embryos. Front Plant Sci 11:522. https:// doi.org/10.3389/fpls.2020.00522

Lin T, Zhou C, Chen G et al (2020) Heterosis-associated genes confer high yield in super hybrid rice. Theor Appl Genet 133:3287-3297

Lindhout P, Meijer D, Schotte T, Hutten RCB, Visser RGF, Eck HJ (2011) Towards F1 hybrid seed potato breeding. Potato Res 54:301-312

Lindhout P, De Vries M, Ter Maat M, Ying S, Viquez-Zamora M, van Heusden S (2017) Hybrid potato breeding for improved varieties. In: Wang-Pruski G (ed) Achieving sustainable cultivation of potatoes, vol 1. Breeding, nutritional and sensory quality. Burleigh \& Dodds, Cambridge (UK) pp, pp 1-24

Luna J, Dufour D, Tran T et al (2021) Post-harvest physiological deterioration in several cassava genotypes over sequential harvests and effect of pruning prior to harvest. Int J Food Sci Technol 56:1322-1332. https://doi.org/10.1111/ijfs.14711

Malik AI, Kongsil P, Nguyễn VA et al (2020) Cassava breeding and agronomy in Asia-50 years of history and future directions. Breed Sci. https://doi.org/10.1270/jsbbs. 18180

Maredia MK, Byerlee D (2000) Efficiency of research investments in the presence of international spillovers: wheat research in developing countries. Agric Econ 22:1-16

Mateo N, Ortiz R (2013) Resource use efficiency revisited. In: Hershey $\mathrm{CH}$, Neate $\mathrm{P}$ (eds) Eco-efficiency: from vision to reality. CIAT Publication No. 381, Cali

Mbanjo EGN, Rabbi IY, Ferguson ME et al (2021) Technological innovations for improving cassava production in Sub-Saharan Africa. Front Genet. https://doi.org/10.3389/fgene.2020.623736

Meenakshi JV, Johnson N, Manyong VM et al (2007) How cost-effective is biofortification in combating micronutrient malnutrition? An Ex Ante Assessment World Dev 38:64-75

Mehta D, Stürchler A, Anjanappa RB et al (2019) Linking CRISPRCas9 interference in cassava to the evolution of editing-resistant geminiviruses. Genome Biol. https://doi.org/10.1186/ s13059-019-1678-3

Melchinger AE, Utz HF, Piepho HP, Zeng ZB, Schön CC (2007) The role of epistasis in the manifestation of heterosis: a systemsoriented approach. Genetics 177:1815-1825

Mendoza HA, Haynes FL (1974) Genetic basis of heterosis for yield in the autotetraploid potato. Theor Appl Genet 45:21-25

Mikel MA, Dudley JW (2006) Evolution of North American dent corn from public to proprietary germplasm. Crop Sci 46:1193-1205

Morris WL, Taylor MA (2019) Improving flavor to increase consumption. Am J Pot Res 96(2):195-200. https://doi.org/10.1007/ s12230-018-09702-7

Mtunguja MK, Laswai HS, Kanju E, Ndunguru J, Muzanil YC (2016) Effect of genotype and genotype by environment interaction on total cyanide content, fresh root, and starch yield in farmer-preferred cassava landraces in Tanzania. Food Sci Nutr 4:791-801

Musembi KB, Mwangi Githiri S, Yencho GC, Sibiya J (2015) Combining ability and heterosis for yield and drought tolerance traits under managed drought stress in sweetpotato. Euphytica 201: 423-440. https://doi.org/10.1007/s10681-014-1230-1

Ndjouenkeu R, Kegah FN, Teeken B et al (2021) From cassava to gari: mapping of quality characteristics and end-user preferences in Cameroon and Nigeria. Int J Food Sci Technol 56:1223-1238. https://doi.org/10.1111/ijfs. 14790
Okechukwu RU, Dixon AGO (2008) Genetic gains from 30 years of cassava breeding in Nigeria for storage root yield and disease resistance in elite cassava genotypes. J Crop Improv 22:181-208

Okeke UG, Akdemir D, Rabbi I, Kulakow P, Jannink JL (2017) Accuracies of univariate and multivariate genomic prediction models in African cassava. Genet Sel Evol 49:88. https://doi.org/10. 1186/s12711-017-0361-y

Okogbenin E, Setter TL, Ferguson M (2014) Phenotyping cassava for adaptation to drought. In: Monneveux P, Okono Ribaut JM., A, (eds) Drought phenotyping in crops: from theory to practice. Frontiers Media, Lausanne

Ortiz D, Sánchez T, Morante N (2011) Sampling strategies for proper quantification of carotenoids content in cassava breeding. J Plant Breed Crop Sci 3:14-23

Peprah BB, Agyeman A, Parkes E et al (2016) Stability, agronomic performance and genetic variability of 10 cassava genotypes in Ghana. J Plant Breed Crop Sci 8:157-167

Perera PIP, Dedicova B, Ordonez C, Kularatne JDJS, Quintero M, Ceballos H (2012) Recent advances in androgenesis induction of cassava (Manihot esculenta Crantz). Acta Hortic 961:319-325

Pineda M, Yu B, Tian Y et al (2020) Effect of pruning young branches on fruit and seed set in cassava. Front Plant Sci 11:1107. https:// doi.org/10.3389/fpls.2020.01107

Pineda M, Morante N, Salazar S et al (2020) Induction of earlier flowering in cassava through extended photoperiod. Agronomy. https://doi.org/10.3390/agronomy10091273

Pingali PL (2012) Green Revolution: impacts, limits, and the path ahead. PNAS 109(31):12302-12308

Pingali P, Kelley T (2007) The role of international agricultural research in contributing to global food security and poverty alleviation: the case of the CGIAR. In: Evenson R, Pingali P (eds) Handbook of agricultural economics, vol 3. Elsevier, New York, pp 2382-2418

Quero-García J, Letourmy P, Ivancic A et al (2009) Hybrid performance in taro (Colocasia esculenta) in relation to genetic dissimilarity of parents. Theor Appl Genet 119:213-221

Rabbi IY, Kayondo SI, Bauchet G et al (2020) Genome-wide association analysis reveals new insights into the genetic architecture of defensive, agro-morphological and quality-related traits in cassava. Plant Mol Biol. https://doi.org/10.1007/ s11103-020-01038-3

Ramisch J (2012) 'This field is our church': The social and agronomic challenges of knowledge generation in a participatory soil fertility management project. In: Sumberg JE, Thompson J (eds) Contested agronomy: agricultural research in a changing world. Taylor and Francis, New York, pp 146-174

Ramos Abril LN, Pineda LM, Wasek I, Wedzony M, Ceballos H (2019) Reproductive biology in cassava: stigma receptivity and pollen tube growth. Commun Integr Biol 12:96-111

Renkow M, Byerlee D (2010) The impacts of CGIAR research: a review of recent evidence. Food Policy 35:391-402

Rojanaridpiched C, Vichukit V, Ceballos H, Aeimnaka P, Pumichai C, Piyachomkwan K (2020) Development of Waxy Starch Cassava Varieties in Thailand. 9thStarch World Asia Conference (CMT). Bangkok, Thailand

Rokka VM (2009) Potato haploids and breeding. In: Touraev A, Forster BP, Jain SM (eds) Advances in haploid production in higher plants. Springer, Berlin, pp 199-208

Rolland-Sabaté A, Sánchez T, Buléon A et al (2012) Structural characterization of novel cassava starches with low and high-amylose contents in comparison with other commercial sources. Food Hydrocoll 27:161-174

Rolland-Sabaté A, Sanchez T, Buléon A et al (2013) Molecular and supra-molecular structure of waxy starches developed from cassava (Manihot esculenta Crantz). Carbohydr Polym 92:1451-1462 
Rosenthal DM, Slattery RA, Miller RE et al (2012) Cassava aboutFACE: Greater than expected yield stimulation of cassava (Manihot esculenta) by future $\mathrm{CO} 2$ levels. Glob Change Biol 18:2661-2675

Ruiz-Vera UM, De Souza AP, Ament MR, Gleadow RM, Ort DR (2020) High sink strength prevents photosynthetic down-regulation in cassava grown at elevated $\mathrm{CO} 2$ concentration. J Exp Bot. https://doi.org/10.1093/jxb/eraa459

Sagrilo E, Soares VP, Fo., Pequeno MG, Gonçalves-Vidigal MC, Kvitschal MV, (2008) Dry matter production and distribution in three cassava (Manihot esculenta Crantz) cultivars during the second vegetative plant cycle. Braz Arch Biol Technol 51:1079-1087

Sánchez T, Dufour D, Moreno IX, Ceballos H (2010) Comparison of pasting and gel stability of waxy and normal starches from cassava, potato, maize, and rice under thermal, chemical and mechanical stress. J Agric Food Chem 58:5093-5099

Sánchez T, Ceballos H, Dufour D et al (2014) Carotenoids and dry matter Prediction by NIRS and hunter color in fresh cassava roots. Food Chem 151:444-451

Scott GJ (2021) A review of root, tuber and banana crops in developing countries: past, present and future. Int J Food Sci Technol 56:1093-1114. https://doi.org/10.1111/ijfs.14778

Selvaraj MG, Montoya PME, Atabori J, French T, Pridmore T (2019) A low-cost aeroponic phenotyping system for storage root development: unravelling the below-ground secrets of cassava (Manihot esculenta). Plant Methods 15(1):131. https://doi.org/10.1186/ s13007-019-0517-6

Selvaraj MG, Valderama M, Guzman D, Valencia M, Ruiz H, Acharjee A (2020) Machine learning for high-throughput field phenotyping and image processing provides insight into the association of above and below-ground traits in cassava (Manihot esculenta Crantz.). Plant Methods. https://doi.org/10.1186/ s13007-020-00625-1

Sharma C, Jayanty SS, Chambers E, Talavera M (2020) Segmentation of potato consumers based on sensory and attitudinal aspects. Foods. https://doi.org/10.3390/foods9020161

Sheat S, Fuerholzner B, Stein B, Winter S (2019) Resistance against cassava brown streak viruses from Africa in cassava germplasm from South America. Front Plant Sci 10:567. https://doi.org/10. 3389/fpls.2019.00567

Silva Souza L, Parreira Diniz R, Neves R de J, Cunha Alves AAC, de Oliveira EJ (2018) Grafting as a strategy to increase flowering of cassava. Sci Hortic 240:544-551. https://doi.org/10.1016/j. scienta.2018.06.070

Snapp S (2002) Quantifying farmer evaluation of technologies: The mother and baby trial design. In: Bellon MR, Reeves J (eds) Quantitative analysis of data from participatory methods in plant breeding. CIMMYT, Mexico

Ssemakula G, Dixon A (2007) Genotype x environment interaction, stability and agronomic performance of carotenoid-rich cassava clones. Sci Res Essay 2:390-399

Steinke J, van Etten J, Mejía Zelan P (2017) The accuracy of farmer-generated data in an agricultural citizen science methodology. Agron Sustain Dev 37:32. https://doi.org/10.1007/ s13593-017-0441-y

Stuber CW (1994) Heterosis in plant breeding. Plant Breed Revs $12: 227-251$

Teeken B, Olaosebikan O, Haleegoah J et al (2018) Cassava trait preferences of men and women farmers in Nigeria: implications for breeding. Econ Bot 72:263-277
Teeken B, Agbona A, Bello A, Olaosebikan O, Alamu E, Adesokan M, Awoyale W, Madu T, Okoye B, Chijioke U, Owoade D, Okoro M, Bouniol A, Dufour D, Hershey C, Rabbi I, Maziya-Dixon B, Egesi C, Tufan H, Kulakow P (2021) Understanding cassava varietal preferences through pairwise ranking of gari-eba and fufu prepared by local farmer-processors. Int J Food Sci Technol 56:1258-1277

Thiele G, Dufour D, Vernier P et al (2021) A review of varietal change in roots, tubers and bananas: consumer preferences and other drivers of adoption and implications for breeding. Int J Food Sci Technol 56:1076-1092. https://doi.org/10.1111/ijfs.14684

Tran T, Zhang X, Ceballos H et al (2021) Correlation of cooking time with water absorption and changes in relative density during boiling of cassava roots. Int J Food Sci Technol 56:1193-1205. https://doi.org/10.1111/ijfs.14769

Valle JF (2021) Streamlining Citizen Science for Crop Variety Evaluation of Roots, Tubers and Bananas (RTB): a review of trait preferences and participatory research in RTB crops. https://cgspa ce.cgiar.org/handle/10568/111047

van Etten J, de Sousa K, Aguilar A et al (2019) Crop variety management for climate adaptation supported by citizen science. PNAS 116(10):4194-4199

van Etten J, Beza E, Calderer L et al (2019) First experiences with a novel farmer citizen science approach: crowdsourcing participatory variety selection through on-farm triadic comparisons of technologies (TRICOT). Expl Agric 55(S1):275-296

van Etten J, Abidin E, Arnaud D et al (2020) The tricot citizen science approach applied to on-farm variety evaluation: methodological progress and perspectives. Lima, Peru: CGIAR Research Program on Roots, Tubers and Bananas (RTB). RTB Working Paper. No 2021-2. www.rtb.cgiar.org DOI: https://doi.org/10. 4160/23096586RTBWP20212

Wang HL, Cui XY, Wang XW, Liu SS (2016) First report of Sri Lankan cassava mosaic virus infecting cassava in Cambodia. Plant Dis 100:1029. https://doi.org/10.1094/PDIS-10-15-1228-PDN

Wang J, Santiago E, Caballero A (2016) Prediction and estimation of effective population size. Heredity. https://doi.org/10.1038/ hdy. 2016.43

Wijnker E, van Dun K, de Snoo CB et al (2012) Reverse breeding in Arabidopsis thaliana generates homozygous parental lines from a heterozygous plant. Nat Genet 44:467-470. https://doi.org/10. 1038/ng.2203

Wolfe MD, Rabbi IY, Egesi C et al (2016) Genome-wide association and prediction reveals the genetic architecture of cassava mosaic disease resistance and prospects for rapid genetic improvement. Plant Genome 9:1-13. https://doi.org/10.3835/plantgenome2015. 11.0118

Wolfe MD, Pino Del Carpio D, Alabi O et al (2017) Prospects for genomic selection in cassava breeding. Plant Genome. https:// doi.org/10.3835/plantgenome2017.03.0015

Xu Y, Crouch JH (2008) Marker-assisted selection in plant breeding: from publications to practice. Crop Sci 48:391-407

Zhong Y, Chen B, Li M et al (2020) A DMP-triggered in vivo maternal haploid induction system in the dicotyledonous Arabidopsis. Nat Plants 6:466-472

Publisher's Note Springer Nature remains neutral with regard to jurisdictional claims in published maps and institutional affiliations. 